\title{
Genomic and Experimental Investigations of Auriscalpium and Strobilurus Fungi Reveal New Insights into Pinecone Decomposition
}

\author{
Panmeng Wang ${ }^{1}$, Jianping $\mathrm{Xu}^{2}$, Gang $\mathrm{Wu}^{1}$, Tiezhi $\mathrm{Liu}^{3}$, and Zhu L. Yang ${ }^{1}$ \\ ${ }^{1}$ Kunming Institute of Botany Chinese Academy of Sciences \\ ${ }^{2}$ McMaster University \\ ${ }^{3}$ Chifeng University
}

June 24, 2021

\begin{abstract}
Saprophytic fungi play vital roles in nutrient cycling and ecosystem dynamics. However, our understanding of how saprophytic fungi interact with each other to decompose organic matter is very limited. Here, we conducted field surveys of pineconecolonizing/decomposing mushrooms, investigated the chemical compositions of decomposing pinecones, and analyzed seven new genomes of three pairs of mushrooms in the genera Auriscalpium and Strobilurus with substrate specificities. Each pair of mushrooms successively colonizes the pinecones of a different pine species: A. orientale-S. luchuensis on Pinus yunnanensis, A. vulgare-S. stephanocystis on Pinus sylvestris, and A. microsporum-S. pachcystidiatus/S. orientalis on Pinus armandii. Our analyses revealed evidence for both competition and cooperation between Auriscalpium and Strobilurus fungi during pinecone decomposition. Their successive colonization of the two fungi groups with complementary profiles of carbohydrate-active enzymes enabled efficient decomposition and utilization of pinecones. The Auriscalpium fungi are highly effective at utilizing the recalcitrant primary organic carbons such as lignin and hemicellulose in freshly fallen pinecones. The decomposition by Auriscalpium fungi enabled the successive colonization by Strobilurus fungi which can produce an arsenal of secondary metabolites such as strobilurins to inhibit other fungi and have abundant carbohydrate-active enzymes for effective utilization of the remaining organic compounds in pinecones.
\end{abstract}

\section{Introduction}

Decomposition of organic matter is vitally important in ecosystem processes such as carbon and nitrogen cycling, soil formation and biodiversity maintenance (García-Palacios, McKie, Handa, Frainer, \& Hattenschwiler, 2016; Giweta, 2020). In nature, decomposition is highly dynamic with ever-changing interactions among decomposers and between substrate composition and successive development of microbial communities (Baldrian et al., 2016; Katagiri et al., 2019). Fungi are key components of the microbial communities in most natural decompositions with different fungal species and strains interacting with each other in multiple ways, leading to complete degradation of complex organic compounds such as lignocelluloses in wood and plant litter. Indeed, there is emerging evideince showing orderly succession among fungal members of microbial communities through the different stages of lignocellulose decomposition (Eichlerova et al., 2015).

As one of the most important members of microbial communities in forest ecosystems, saprophytic fungi (SPF) have diverse degradation mechanisms and play key roles in the degradations of dead organic matters (Baldrian et al., 2016; Rajala, Peltoniemi, Hantula, Makipaa, \& Pennanen, 2011). However, due to the limited resources across space and time in most ecological niches and the presence of many (potential) competitors, fungal decomposers have evolved mechanisms to allow them successfully colonizing one to several substrates/ecological niches (Boddy, 2000). Those colonizing only one type of ecological niche are 
called ecological "specialists" while others capable of colonizing many types of ecological niches are called "generalists" (Moor, Norden, Penttil, Siitonen, \& Snll, 2020). There are many who are in-between the obligate specialists and broad generalists, including those that are primarily found in one ecological niche but are capable of surviving and growing in other niches (Moor et al., 2020). Evidence for ecological specializations in fungi has been recorded since ancient times (Baldrian et al., 2016). In addition, most ecological niches and substrates have successions where different fungal communities may dominate different phases of substrate decomposition (Eichlerova et al., 2015).

There are many factors that can impact the composition and structure of saprophytic fungal community. Among these factors, the chemical composition of substrates plays a major role (Krah et al., 2018; Rajala, Peltoniemi, Pennanen, \& Makipaa, 2010). For example, on woody substrates, the decomposition rate of polymeric lignocellulosic components changes through the decomposition process, due to changes in substrate compositions and in the types and relative abundances of different microbes and their enzymes involved in degradations (Šnajdr et al., 2011). Traditionally, saprophytic fungi are broadly classified into two types, namely ligninolytic white-rot (WR) and cellulolytic brown-rot (BR), although there is a continuum between these two types (Boddy, 2000; Riley et al., 2014). In the process of decomposition, interaction (including competition) among fungi is likely very common, affecting the distribution, abundance, and the order of occurrence among these fungi in natural communities (Edman \& Eriksson, 2016).

Different interaction strategies among species can lead to different orders of SPF emergence on substrates. Both biotic and abiotic factors can also influence their order of emergence and interactions (Boddy, 2000; Edman \& Fällström, 2013; Fukami et al., 2010). Fungal competition on substrates is commonly classified into two major functional types: primary resource capture and secondary resource capture (Boddy, 2000; Sasha \& Bhatnagar, 2019; Song, Vail, Sadowsky, \& Schilling, 2012). Success of SPF in primary resource capture mainly depends on the ability to utilize previously uncolonized resources and on their ability to resist antifungal compounds in those substrates. In contrast, success in secondary resource capture mainly relies on antagonistic mechanisms, with different species competing with each other to obtain sufficient nurients for survival and reproduction (Boddy, 2000). Often, changes in microbial communities during decomposition are related to the secretion of antagonistic enzymes and metabolites (Boddy, 2000). On the one hand, SPFs have the ability to secrete various carbohydrate-active enzymes (CAZymes) to decompose and utilise the major constituents such as lignin, cellulose, and hemicellulose in wood and plant litter, facilitating nutrient cycling and energy flow in forest ecosystem (Cantarel et al., 2009; Kohler et al., 2015; Zhao, Liu, Wang, $\& \mathrm{Xu}, 2013)$. Indeed, the compositions and characteristics of CAZymes often differ among fungi, likely shaped by characteristics of their substrates and the degree of adaptation to the specific environmental conditions (Zhao et al., 2013). Therefore, to understand decomposition, it is particularly important to study the compositions and characteristics of CAZymes to clarify the potential mechanisms for different nutritional modes, infection, and substrates specificity/preference (de Wit et al., 2012; Martin, Kohler, Murat, VeneaultFourrey, \& Hibbett, 2016; Nagy et al., 2016; Park, Jeong, \& Kong, 2018; Zhao et al., 2013; Zhao et al., 2019). On the other hand, fungal secondary metabolites (SMs) are known to play crucial roles in defence against pathogens and competitors and provide advantages for their producers and/or those who have resistant mechanisms. Along with CAZymes, fungal SMs can provide important information for understanding the chemical basis of niche specialization during decompositions (Arfi, Levasseur, \& Record, 2013; Saha \& RoyBarman, 2018).

Multiple groups of SPFs are frequently involved in plant litter decomposition. These fungi belong to diverse clades, but some of them are functionally interchangeable (Arfi et al., 2013; Niemela, Renvall, \& Pentilla, 1995; Zhang \& Wei, 2016; Figure S1). In forest ecosystems, due to its extractive composition and the presence of antifungal compounds such as resin, pinecone is a specialized substrate and a unique habitat for fungi (https://mycocosm.jgi.doe.gov/Aurvu1/Aurvu1.home.html). Indeed, only species in a few fungal genera (e.g., Strobilurus ,Auriscalpium , Baeospora and Mycena ) are known to colonize and decompose pinecones. Among these genera,Auriscalpium and Strobilurus are highly specialized on pinecones (Qin, Horak, Popa, Rexer, \& Yang, 2018; Wang \& Yang, 2019). Interestingly, species of Auriscalpium and Strobilurususually share the dead cones of the same plant species in a chronological order, with Auriscalpium fungi often appearing on 
newly fallen cones, while those of Strobilurus typically occurring on highly rotten cones during later stages of decomposition. At present, the mechanisms for their succession during pinecone decomposition are unknown.

In this study, we investigated three pinecone substrate-fungus pairs from Europe and East Asia to understand the potential mechanisms for substrate specificities and ecological succession during pinecone decomposition. The three fungal pairs as well as their substrates were $A$. orientale $-S$. luchuensis on cones of Pinus yunnanensis, A . vulgare $-S$.stephanocystis on cones of $P$. sylvestris, and $A$. microsporum $-S$.pachcystidiatus $/ S$.orientalis on cones of $P$. armandii . We obtained the genome sequences of these seven fungal species and quantified the main chemical compounds during pinecone decomposition. Our analyses revealed both shared and unique features in their substrate specificity and ecological successions among these fungal pairs.

\section{Materials and methods}

Material collections, greenhouse planting experiment, fungal strains, media and culture conditions

The records on the geographical distributions and substrate information of $A$. vulgare and $S$. stephanocystis were extracted from data deposited in the Global Biodiversity Information Facility (GBIF; https://www.gbif.org/). The information on substrates and distributions of the following four species $A$.orientale, A. microsporum, $S$.luchuensis and $S$. pachycystidiatus was primarily from the published literature and our own observations during field investigations in China. In order to directly observe the characteristics of pinecone decomposition by Auriscalpium andStrobilurus, a planting experiment was conducted in the greenhouse using the cones of $P$. armandii fully colonized by $A$. microsporum collected in the forest in which bothAuriscalpium and Strobilurus existed.

All seven strains used for de novo sequencing were dikaryotic strains isolated directly from the fruiting bodies from wild mushrooms. Among these, the following five species and strains were collected in Yunnan Province, China: A .microsporum(strain AU-H-210), A .orientale (strain AU-Y-A),S .luchuensis (strain Y-Y2D), S .pachycystidiatus (strain Y-H-6C) and $S$.orientalis (strain K-1-1). The remaining two A vulgare (CBS 236.39) and $S$.stephanocystis (CBS 113577) were obtained from the Westerdijk Fungal Biodiversity Institute (CBS, Fungal Biodiversity Centre in Netherlands). The strains were stored at $4{ }^{\circ} \mathrm{C}$ on MEA solid medium (1\% malt extract, $0.1 \%$ peptone and $1.5 \%$ agar). Vegetative mycelia of those strains were cultivated in MEA liquid medium ( $1 \%$ malt extract and $0.1 \%$ peptone) in the dark at $23{ }^{\circ} \mathrm{C}$ for $7-25$ days, and then the mycelia were collected for DNA extraction and whole genome sequencing (Mayjonade et al., 2016).

\section{Measurements of pinecone compositions}

For each type of pinecone, we analyzed the complex organic compounds at two different states: (i) newly fallen cones, and (ii) cones being decomposed by fungi in the genus Auriscalpium. The contents of cellulose, hemicellulose and lignin were quantified using the automatic fiber analyzer according to the ANKOM 2000i instructions (https://www.ankom.com/technical-support/fiber-analyzer-a2000). We used the TAPPI standards in cones of $P$. armandii,$P$. yunnanensis and $P$. sylvestris at KIB (Kunming Institute of Botany, CAS) as references. The pectin contents in these samples were quantified by using the method of sulfuric acid-carbazole colorimetry (Zhu, Huang, Wu, Chen, \& He, 2017). Analyses for all samples were carried in decuplicate.

\section{Genome sequencing, assembly and protein-coding gene predictions}

To yield a high-quality genome assembly, the genomes were sequenced using a whole genome shotgun sequencing strategy with a combined strategy that included both the Pacific Biosciences RS II (Pacific Biosciences, Menlo Park, CA, USA) and Illumina MiSeq platforms (Illumina Inc., San Diego, CA, USA) by Biomarker Technologies Co, LTD (Beijing, China). The PacBio long reads were corrected and assembled using Canu for draft genomes (Koren et al., 2017). FinisherSC was used to improve the contiguity of draft genomes (Lam, Labutti, Khalak, \& Tse, 2015), and pilon was used to polish the draft genomes with collected Illumina data by Musket (Liu, Jan, \& Bertil, 2013; Walker et al., 2014). HaploMerger2 was used to separate the two haploid sub-assemblies from the assembly (Huang et al., 2012; Huang, Kang, \& Xu, 2017). Ab initio predictions 
were carried out using the reference protein domains ofPeniophora sp. andArmillaria ostoyae (Sipos et al., 2017; Varga et al., 2019) for Auriscalpium and Strobilurus, respectively. Based on the two high-quality sequencing datasets described above, the protein-coding gene set of genomes were refined following the GETA gene annotation method ( $\mathrm{Li}$ et al., 2020). BUSCOs using database of fungi_odb9 were applied to our gene predictions.

\section{Identification ofcarbohydrate-active enzymes (CAZymes) and lignocellulolytic genes and Swiss-Prot annotation}

Carbohydrate-active enzymes (CAZymes) were identified by using a combination of pipelines that included the HMM and BLASTP algorithms as used by Chen et al., (2016). CAZyme annotation by BLASTP algorithms used a cutoff e-value $<1 \mathrm{e}-5$ and coverage $>20 \%$. CAZyme annotation by HMM algorithms used a cutoff e-value $<1 \mathrm{e}-5$ for alignments of $>80$ amino acids, and for alignments of $<80$ amino acids, we used an e-value of $<1 \mathrm{e}-3$ and coverage $>25 \%$. Perl program was used to extract the annotation results that conform to the two methods as the final result. For Swiss-Prot annotation, the BLASTP algorithm was used to align the protein sequences to Swiss-Prot (Bairoch, Boeckmann, Ferro, \& Gasteiger, 2004) with e-value < 1e-5. Lignocellulolytic genes (cellulase, hemicellulase, pectinase, lignin oxidase and lignin degrading auxiliary enzymes) were identified mainly by the Swiss-Prot annotation with keywords as described by Chen et al., (2016) in their Table S20. In the following analyses, lignin oxidases and lignin degrading auxiliary enzymes encoded by lignocellulolytic genes were combined into one category called ligninases (Chen et al., 2016).

\section{Principal component analyses (PCA) and heatmap analyses of CAZymes and lignocellulolytic genes}

In PCA of CAZymes, organisms are cluster with others which have the similar nutrient patterns to determine the rot patterns of fungi (Riley et al., 2014). Here, PCA was used to cluster WR and BR fungi based on the diversity of their CAZymes. The CAZymes number matrix of wood decay fungi (WDF) from the following species was used as input: Galerina marginata (abbreviated as "gama"), A . orientale("auor"), Heterobasidion annosum ("hean"), Stereum hirsutum ("sthi"), A . vulgare ("auvu"), Punctularia strigosozonata ("pust"), A .microsporum ("aumi"), Fomitiporia mediterranea("fome"), S . pachycystidiatus ("stpa"), S .luchuensis ("stlu"), Dichomitus squalens ("disq"), Trametes versicolor ("trve"), Phanerochaete chrysosporium ("phch"), S . stephanocystis ("stst"), Phanerochaete carnosa ("phca"), S . orientalis("stor"), Wolfiporia cocos ("woco"), Gloeophyllum trabeum ("gltr"), Fomitopsis pinicola ("fopi"), Dacryopinax primogenitus ("dapr"), Serpula lacrymans ("sela") and Coniophora puteana ("copu") (Eastwood et al. 2011; Floudas et al. 2012; Martinez et al. 2004; Ohm et al. 2014; Olson et al., 2012; Riley et al., 2014; Suzuki et al. 2012).

Among these species, phca, phch, hean, sthi, gama, disq, trve, fome and pust belonged to WR fungi, while copu, gltr, fopi, woco, dapr and sela belonged to BR fungi (Chen et al., 2016; Riley et al., 2014). The online OmicShare tools (http://www.omicshare.com/tools) were used to generate the illustrations, heatmaps, and other outputs from PCA and statistical analysis. Adobe Photoshop (PS) and Adobe Illustrator (AI) were used for image editing and finalization.

\section{Analyses of enzymes on resin decomposition}

By adding latex to media, Oghenekaro, Kovalchuk, Raffaello, Camarero, \& Asiegbu, (2020) identified that some genes had elevated expressions in $R$. microporus . Latex is a complex emulsion that includes a diversity of chemicals such as proteins, alkaloids, carbohydrates, oils, tannins, and resins that coagulate on exposure to air (Konno, 2011). It is commonly produced by plants after tissue injury and serve as a defense against pathogens and pests (Oghenekaro et al., 2020). Here we used the high expressed genes induced by latex treatment in $R$.microporus to infer the distributions of these genes in the seven fungi analyzed in our study. Using those genes in $R$.microporus as references, we identified the homologous genes in our genomes through BLASTP algorithms with a cut off e-value $<1 \mathrm{e}-5$ as showed above.

\section{Secondary metabolites (SMs) in Auriscalpium andStrobilurus}

SMs genes are frequently located in gene clusters of microorganisms (Keller, Turner, \& Bennett, 2005), and 
they may have important physiological and ecological significances with antifungal, antibacterial, antitumor, antiviral, antialgal, immune-suppressive and other biological effects (Devi et al., 2019). Here, for our seven genomes, SM gene clusters were determined using a web-based analysis platform named AntiSMASH fungal 4.0.0 (Blin et al., 2013).

\section{Results}

\section{Ecological characteristics of fungi in Auriscalpium andStrobilurus}

The temporal and trophic niches as reported in the literature and our own observations for Auriscalpium and Strobilurus fungi in this study are summarized in Figure 1 and Table S6. The data showed clear differences between these two groups of fungi in their temporal distributions during pinoecone decomposition (Figure 1; Table S6). Specifically, fruiting bodies of $A$. vulgare are mostly found on newly fallen cones of $P$. sylvestris, $P$.pinaster,$P$. halepensis and $P$. mugoin September and October, while those of $S$. stephanocystismostly appear on highly rotten cones already decomposed by $A$.vulgare in May. Similarly, $A$. orientale mainly appears on newly fallen cones of $P$. yunnanensis,$P$.tabuliformis,$P$. densiflora,$P$.densata,$P$. massoniana and $P$.hwangshanensis in August, while $S$. luchuensis on highly rotten cones already decomposed by $A$. orientale. In addition, $A$. microsporum mostly produces fruitbodies in September on newly fallen cones of $P$. armandii and with fruiting bodies of $S$. pachycystidiatus found in June on cones newly decomposed by $A$. microsporum, and $S$.orientalis in October on highly decomposed cones by $A$.microsporum and/or $S$. pachycystidiatus. The ecological characteristics of colonization and fruiting by Auriscalpium and Strobilurus fungi on pinecones as observed in the field were similarly found in our greenhouse fruiting experiment. Under the greenhouse culture condition, fruiting bodies of $A$. microsporum formed first from July to September, then $S$. pachcystidiatus appeared from May to July over the next three years, and finally $S$. orientalis appeared from October to December. Togather, these greenhouse observations are consistent with our field observations on the ecological successions of these fungi on pinecones (Figure S2).

\section{Composition analyses of pinecones}

Among newly fallen cones, that of $P$. yunnanensis showed the highest contents of lignin and hemicellulose, but the least amounts of cellulose and pectin. In contrast, the cones of $P$.armandii showed the highest contents of cellulose and pectin, but the least amount of lignin (Figure 3b; Table S2). In addition to the least amount of hemicellulose, the other components in the cone of $P$. sylvestris are between those in the cones of the other two species (Figure 3b; Table S2). Compared with the newly fallen cones, the cones already decomposed by corresponding Auriscalpium fungi had reduced relative proportions of lignin and hemicellulose and increased relative proportions of cellulose and pectin (Figure 4a-c; Table S2).

Genome sequencing, data preprocessing, assembly, general genome features, protein-coding gene prediction and functional annotation

The general features of the seven genomes that we sequenced are summarized in Table 1. Raw data were generated with Pacbio sequencing and Illumina sequencing with coverage 85.84-386.08X and 101.04-206.85X, respectively (Table S7). Among the Auriscalpium species, $A$. vulgare had the largest genome (51.68 Mb), followed by $A$. orientale $(45.40 \mathrm{Mb})$, and $A$. microsporumhad the smallest genome (43.46 Mb) (Table 1). Among the species ofStrobilurus, $S$. pachycystidiatus had the largest genome $(51.82 \mathrm{Mb})$, followed by $S$. orientalis $(51.25 \mathrm{Mb})$ and $S$. luchuensis $(46.71 \mathrm{Mb})$, and $S$.stephanocystis had the smallest genome (42.38 $\mathrm{Mb}$ ) (Table 1). The sets of annotated protein-coding genes in the seven assembled genomes were estimated to be $92.4 \%-100 \%$ complete (Table S8). Among theAuriscalpium species, A . orientale had the most coding genes (16958), followed by $A$. microsporum (15333), and $A$. vulgare had the least coding genes (13636). Among the taxa of Strobilurus, $S$. orientalis has the most coding genes (18509), followed by $S$. pachycystidiatus(18157) and $S$. luchuensis (16796), and $S$.stephanocystis had the least number of coding genes (16439).

Identification of CAZymes and lignocellulolytic genes in fungi of Auriscalpium and Strobilurus

The number of CAZymes in A . vulgare, A .microsporum, A . orientale, S .stephanocystis, S . luchuensis 
, $S$.pachycystidiatus and $S$. orientalis were 450,425, 464, 532, 542, 583 and 621 , respectively (Figure $2 \mathrm{~b}$; Table S1). Our statistical analyses revealed that the average number of CAZymes inAuriscalpium fungi is significantly lower than that inStrobilurus such as AA5, CBM18, CBM67, CE12, CE16, CE4, CE8, GH105, GH12, GH127, GH128, GH13, GH135, GH16, GH17, GH18, GH27, GH28, GH29, GH35, GH43, GH45, GH5, GH53, GH55, GH71, GH76, GH93, GT1, GT15, GT17, GT33, GT4, GT8, PL1 and PL4 (Table S3). The average number of CAZymes in Auriscalpium fungi is significantly more than that inStrobilurus only in seven gene families including AA2, GH2, GH3, GH15, GH31, GH109 and PL8. Similarly, in the statistical analyses, the comparison of CAZymes between Auriscalpium and other WR fungi, and the comparison of CAZymes between Strobilurus and other WR fungi are shown in Table S4 and Table S5, respectively. The average number of CAZymes inAuriscalpium fungi is significantly more than that in other WR fungi only in six gene families, however the average number of CAZymes in Strobilurus fungi is significantly more than that other WR fungi in 31 gene families (Tables S4-S5).

The number of predicted lignocellulolytic genes in A vulgare, A . microsporum, A .orientale, $S$. stephanocystis , S .luchuensis , S . pachycystidiatus and S .orientalis were 112, 97, 111, 107, 106, 122 and 111, respectively (Table S9). For the fungi growing on cones of the same pine species, the proportions of genes encoding ligninases and hemicellulases were higher in Auriscalpium species than those in their correspondingStrobilurus species. In contrast, the proportions of genes encoding cellulases and pectinases were lower in Auriscalpiumthan those in the Strobilurus. For fungi living on cones of $P$. armandii, A . microsporum and $S$ .pachycystidiatus living on relatively newly fallen cones also showed a similar pattern but the difference was less obvious than those in other two fungal pairs. However, $S$. orientalis with a preference of living on more rotten cones showed more obvious differences in their respective enzymes compared with $A$.microsporum .

\section{PCA and Heatmap analyses of CAZymes and lignocellulolytic genes}

Results of the PCA of CAZymes and lignocellulolytic genes showed a clear separation of WR and BR fungi along PCA1 (Figures 2a and S3a). All the fungi in Auriscalpium and Strobilurus cluster together with other WR fungi, consistent with their potent lignin-decomposing ability (Figures 2a and S3a). The heatmap analyses showed that there are unique enzymes within each of the 22 fungi analyzed, which likely reflect the diversity of their preferred substrates (Figures 2c and S3b). In the separate analyses of the two genera, it is apparent that fungi in the two genera showed complementary profiles of carbohydrate-active enzymes (CAZymes) (Figures $3 \mathrm{a}$ and $4 \mathrm{~g}-\mathrm{h}$ ). The results clearly illustrate that there are remarkable differences in the overall pattern of genes between two different genera. At the same time, it demonstrates that the type and number of these CAZymes inAuriscalpium and Strobilurus are different among different fungi, which may partly explain the cause of the substrate specificity (Figure S4a-b). The results of the lignocellulolytic genes are overall consistent with the results of CAZymes (Figure S4c-d). These lignocellulolytic genes are also specific among genera, and there are great differences in the type and number of enzymes among different genera, and each has a set of different enzyme system (Figures $4 \mathrm{~g}-\mathrm{h}$ and $\mathrm{S} 4 \mathrm{c}-\mathrm{d}$ ).

\section{Enzymes related to resin decompositions}

Among the top 10 enzymes showing elevated expressions in the presence of latex in $R$. microporus, our analyses revealed that four of them had an overall greater numbers of genes coding for these enzymes inAuriscalpium fungi than in Strobilurus in the top No. 1, 2, 6 and 10 in Auriscalpium is more than those inStrobilurus (Table 2). Overall, among all the genes, the number of genes coding for peptidase S8 (No. 1) and peptidase S53 (No. 6) in Auriscalpium were significantly higher than that inStrobilurus ( $<<0.05$ ), while the other genes were not significantly different. Of the genes coding for peptidase S8, the average number in Auriscalpium is 20.33, while only 5.4 inStrobilurus (Table 2). In genes coding for peptidase S53, the average numbers in Auriscalpium and Strobilurus were 3.7 and 1.2, respectively (Table 2).

\section{SM clusters in Strobilurus and Auriscalpium}

Terpenes, NRPS (nonribosomal peptide synthetase)-like compounds, and siderophores are among the main groups of SMs shared by fungi in Auriscalpium andStrobilurus and the putative genes coding for enzymes involved in their syntheses are summarized in Table 3. Our analyses showed that T1PKS (type I polyketide 
synthases)-NRPS like and betalactone existed solely in Auriscalpium, while T1PKS-terpene, strobilurin, T1PKS, and indole alkaloids were only found in Strobilurus (Table 3). Our results revealed that the average number of gene clusters for SMs inAuriscalpium fungi was fewer (average 18.33) than that inStrobilurus (average 21.25). As expected, each species ofStrobilurus harbours one SM clusters of strobilurin (Table 3). Fungi in Auriscalpium contain very few gene clusters for NRPS-like but abundant for terpenes, while fungi in Strobilurusare the opposite (Table 3). In summary, the number of genes predicted for the synthesis of NRPSlike, T1PKS, strobilurin and indole alkaloids in Strobilurus fungi is higher than those in Auriscalpiumtaxa.

\section{Discussion}

\section{Successive decomposition of pinecones by fungi of Auriscalpium and Strobilurus}

The successive decomposition of substrates by microbial communities is a common phenomenon (Johnston, Boddy, \& Weightman, 2016; Niemela et al., 1995). Often, the microbial community structure, including the relative abundances of saprophytic fungi, changes significantly during the successive decomposition process (Fukasawa \& Matuoka, 2015). Though occupying the same cological niche, species in these communities may develop unique but complementary strategies to partition the resources in the substrates, leading to temporal niche differentiation and divergence (Friedemann et al., 2016). Here, part of the resource partition is temporal changes of fungi with different fungi use different sets of nutrients within the pinecone. Similar phenomena have been found in other substrates such as plant litters and deadwoods (Baldrian et al., 2016; Edman \& Eriksson, 2016; Herzog, Hartmann, Frey, Stierli, \& Brunner, 2019). In the processe of biodegradation, microbial coordinations with different ecological strategies and certain orders are evident (Herzog et al., 2019; Holmer, Renvall, \& Stenlid, 1997). For example, successions of fungi in temperate forests were considered to be reflected in sugar utilizing fungi, followed by wood structural decaying fungi, and finally residual decaying fungi in some cases (Stokland, Siitonen, \& Jonsson, 2012). This change may be explained in part by nutrients released by the primary decomposers that enabled the colonization of secondary decomposers (Boddy, 2000). However, the successive decomposition of substrates such as deadwood and plant litter requires the action and interaction of many fungi with their fungal community showing a high degree of complexity (Baldrian et al., 2016; Vořřšková \& Baldrian, 2013) For example, Zhang and Wei (2016) had carried out relevant research on fungi in the same forest, in which different fungi will appear on rotten wood in the same state, or even on the same rotten wood. At the same time, a kind of fungus can also exist in different periods of rotten wood (Zhang \& Wei, 2016; Figure S1). Some fungi can only appear in one period, but most fungi can produce fruitbodies at several stages of rotten wood (Zhang \& Wei, 2016; Figure S1). Similarily, Niemela et al., (1995) reported the succession of more than one hundred species of lignicolous Basidiomycetes on fallen trunks in Picea obovata and P .sylvestris . Our study revealed that fungi in Auriscalpiumand Strobilurus possess clear differences in the type and number of CAZymes and lignocellulolytic genes (Figures 2c,3a,4g-h and S3b). Our results indicate that even though they colonize the same pinecones, there are significant divergence and niche differentiation in the utilization of substrates in pinecones between the fungi of the two genera, which leads to the dynamic changes of their emergences on the pinecones.

During the initial decomposition of pinecones, Auriscalpium fungi are the primary colonizers, likely related to their ability to break down resin and their strong capacity to decompose lignin and hemicellulose (Figure 4a-c; Table 2). Such abilities are common among WR fungi (Floudas, Bentzer, Ahrén, Johansson, \& Tunlid, 2020). For example, the fungi ofCeriporiopsis subvermispora , Phellinus pini ,Ganoderma australe, and Phlebia tremellosa specifically degrade lignin and hemicellulose among WR fungi (Weng, Peng, \& Han, 2021). The most compelling evidence supporting the early colonizing ability of Auriscalpium fungi is that their number of peptidases S8 and S53 is far greater than that in Strobilurus fungi. Peptidases S8 and S53 are among the top 10 most up-regulated enzymes in $R$. microporus in the presence of latex (Oghenekaro et al., 2020) (Table 2). The genomic evidence is consistent with Auriscalpium fungi capable of colonizing newly fallen cones and decomposing proteins in resin rapidly. Polo, Pereira, Mazzafera, Flores-Borges, \& Meneau, (2020) showed that lignin and hemicellulose are in the outermost layer of plant cell wall which prevents the cellulolytic enzymes reaching the cellulose and protect plants from microbes. Our analyses demonstrated that the number of genes coding for lignin oxidases (AA2) and hemicellulase (GH3) in Auriscalpium are 
significantly higher than those in Strobilurus (Figure 4g-h; Table S10), and these genes may be related to lignin and hemicellulase decompositions in the outermost layer of pinecones. Once the outer layer is breached, the condition is now more favorable for the subsequent invasion of Strobilurus fungi. With increasing decay, the nutritional composition, physical structure, chemical composition and other aspects of the pinecones have changed, which result in the succession changes of fungal community.

After decomposition by Auriscalpium fungi, the proportions of lignin and hemicellulose in the pinecone would decrease and those of cellulose and pectin proportionally would increase (Figure $4 \mathrm{a}-\mathrm{c}$ ). The subsequent colonization by Strobilurus fungi relies on the residual components of the cones suitable for their growth and replacing the corresponding fungi of Auriscalpium (Figure 5). Similarly, comparing Auriscalpium and Strobilurus grown on the same pinecone, fungi of Strobilurus show decreasing trends of in the number of genes coding for ligninases and hemicellulases, but with higher number of genes coding for cellulase and pectinase, which is broadly consistent with the changes of cone components (Figure 4a-f).Strobilurus pachcystidiatus and $A$. microsporum also show the same pattern, but the differences are not particularly evident, which may relate to the fact that both could grow on newly fallen cones. However, $S$. orientalis grew on the highly rotten cones after decomposition by $A$. microsporum or $S$.pachcystidiatus and it showed a more obvious decrease in the number of ligninase-encoding genes and an increase in the number of cellulase-encoding genes than $S$. pachcystidiatus (Figure 4f).

In addition, in the field, we observed that the fungi of Auriscalpium can decompose cones independently, especially in tropical areas, but the successive decomposition of the two genera is more common. However, we did not observe the decomposition of cones by fungi of Strobilurus independently. In each distribution areas of fungi in Strobilurus, fungi in Auriscalpium could be collected in different periods, and the fungi in Strobiluruscollected all grow on the cones with high degree of decay. For successive decomposition of $P$. armandii' s cones, in addition to the most common combination of $A$.microsporum - $S$. pachcystidiatus $-S$ .orientalis, we also observed the combinations of $A$.microsporum $-S$. pachcystidiatus and A microsporum $-S$. orientalis. Therefore, various situations may occur in the field (Figure 5). Although Strobilurus fungi always appear on cones with a high degree of decomposition, however, the results of our field observation show that compared with Auriscalpium fungi, theStrobilurus fungi can occupy the cone for a long time and fully decompose the cone. There have been reported on the positive correlation between the large amount of CAZymes in the genome and the degradation of plant biomass (Adams et al., 2011), so we speculate that fungi inStrobilurus are the main decomposer with the type and number of CAZymes in Strobilurus being richer than those of Auriscalpium(Figures 2b-c and 3a). In the CAZymes comparisons between the two genera, only seven CAZyme gene families have significantly more genes in the Auriscalpium fungi than in Strobilurus, while the other 36 gene families have more genes in Strobilurus fungi than in Auriscalpium fungi (Table S3), which broadly supports that the subsequent decomposers are main components of substrate decompositions (Song et al., 2012).

\section{Fungual competition of Auriscalpium and Strobilurus on pinecones}

Successive decomposition may be affected by fungul competition. Fungal competitions of Auriscalpium and Strobilurus on substrates correspond to the two functional types: primary resource capture and secondary resource capture, respectively (Boddy, 2000), so that the two genera appear orderly on the cones. On newly fallen cones, there may be hundreds of fungi competing to colonize cones on the surface, which is similar to the situation reported in woods (Coates \& Rayner, 1985). However, the most obvious obstacles for fungi on newly fallen cones are the lack of easily assimilated nutrient matrixs such as lignin and hemicellulose, and the presences of inhibitory substances such as resin, etc. (Abad, Ansuategui, \& Bermejo, 2006). Because of their ability to breakdown these resistant substances, Auriscalpium can gain a competitive edge with other microorganisms in microbial community on newly fallen cones.

With the increase of the decomposition levels, the competitive pressures on the cones gradually increase attributed to the disappearance or reduction of antibacterial or antifungal substances. On one hand, the cones decomposed by the Auriscalpium provide suitable conditions for Strobilurus growth. During this period, the fruitbodies ofStrobilurus and Auriscalpium can co-exist on the same cone (Figure S5f). On the 
other hand, fungi of Strobilurus, as aggressive competitors, produce toxins (e.g. strobilurin) to enhance its competitiveness with Auriscalpium and other microorganisms (Figure S5a-f). For nutrients and spaces, the antagonists can either interact directly with the competitors (Lima, Arru, De Curtis, \& Arras, 1999), or secrete antibiotics to suppress competitors (Wilson et al., 1991). Some studies on antifungal SMs and enzymes produced by fungi with antagonists have been conducted extensively in vitro (Alves, Ferreira, Martins, \& Pintado, 2012; Jonkers et al., 2012). Through SM clusters analyses, we find that the number of SM clusters of the genusAuriscalpium is fewer than that of Strobilurus (Table 3), while all fungi of Strobilurus contain a fungicidal strobilurin cluster whose derivatives have broad spectrum antifungal activity, and, thus, are widely used as biological fungicide (Niego et al., 2021). In addition, the number of NRPS-like in the genomes of Strobilurusis higher than those in Auriscalpium (Table 3). Most of the NRPS, PKS and their combinations have antibacterial and antifungal activities (Fernandes, Costa, Sousa, Zalocha, \& Almeida, 2019), which indicates that the fungi in Strobilurus have stronger antibacterial and antifungal activities than those in $A u$ riscalpium. Aside from the SMs, other factors such as microclimate, the size and quality of nutrient sources can shift the balance between fungal decomposer groups (Boddy, 2000). Thus, in the natural environment, the outcomes of interactions between fungi are variable, leading to differences in community structures.

\section{Conclusion}

Our results reveal that there are differentiations of temporal and trophic niches for fungi of Auriscalpium and Strobilurus. The decompositions of pinecones are frequently completed by these two groups of fungi through successive colonizations, occupying the same physical niche but at different times. The primary colonizers were the fungi of Aurscalpium and the secondary ones wereStrobilurus (Figure 5). The CAZymes of the two groups of fungi are highly unique but also complementary, leading to the complete biodegradation pinecones.

\section{Acknowledgements}

We are grateful to Fungal Biodiversity Centre in Netherlands (CBS) for providing us cultures of Auriscalpium and Strobilurus. We thank Drs. Xiang-Hua Wang, Hong Luo, Yan-Chun Li, Zai-Wei Ge, Feng Bang, Qing Cai, Jiao Qin, Qi Zhao, Xiao-Bin Liu, Mr. Xin Xu, Kui Wu, Hu Sun, Sheng-Wen Zhou, Cong Huang, Yi-Feng An, Jian-Yun Wu, Hua Qu, Peng-Cheng Yuan, and Jian-Wei Liu and Miss. Mei-Xiang Li, Xiao-Xia Ding (KIB), Drs. Xiao-Dan Yu (Shenyang Agricultural University), Tolgor Bau (Jilin Agricultural University), Ping Zhang (Hunan Normal University), Li-Hong Han (Qujing Normal University), Yan-Jia Hao (Anhui Normal University), Mr. Shi-Bin Jiao, Mr. De-Xian Kong for having provided us samples/specimens, collection information and/or color images. We thank Dr. Francis M. Martin (National Research Institute for Agriculture, Food and Environment, France), Dr. Li-Hong Han (QuJing Normal University), Drs. Hong Luo, Bang Feng, Qing Cai (KIB) and Shao-Xing Chen (Anhui Agricultural University), Miss Xiao-Na Shao (Xishuangbanna Tropical Botanical Garden), Yan-Jia Hao (Anhui Normal University) and Jiao Qin (KIB) for their constructive and illuminating comments, criticisms and valuable suggestions. We appreciate Drs. Lian-Fu Chen, Xiao-Bin Liu for valuable information on data analysis. The present research work was supported by the Strategic Priority Research Program of Chinese Academy of Sciences (XDB31000000) and Yunnan Ten-Thousand-Talents Plan-Yunling Scholar Project.

\section{References}

Abad, M., Ansuategui, M., \& Bermejo, P. (2006). Active antifungal substances from natural sources. Archive for Organic Chemistry, 2007 (7), 116-145. doi:10.3998/ark.5550190.0008.711

Adams, A. S., Jordan, M. S., Adams, S. M., Suen, G., Goodwin, L. A., Davenport, K. W., Currie, C. R., \& Raffa, K. F. (2011). Cellulose-degrading bacteria associated with the invasive woodwaspSirex noctilio . The ISME Journal , 5 (8), 1323-1331. doi: 10.1038/ismej.2011.14

Alves, M. J., Ferreira, I. C. F. R., Martins, A., \& Pintado, M. (2012). Antimicrobial activity of wild mushroom extracts against clinical isolates resistant to different antibiotics. Journal of Applied Microbiology , 113 (2), 466-475. doi:10.1111/j.1365-2672.2012.05347.x

Arfi, Y., Levasseur, A., \& Record, E. (2013). Differential gene expression in Pycnoporus coccineus during 
interspecific mycelial interactions with different competitors. Applied and Environmental Microbiology , 79 (21), 6626-6636. doi: 10.1128/AEM.02316-13

Bairoch, A., Boeckmann, B., Ferro, S., \& Gasteiger, E. (2004). Swiss-Prot: juggling between evolution and stability. Briefings in bioinformatics , 5 (1): 39-55. doi: 10.1093/bib/5.1.39

Baldrian, P., Zrustová, P., Tláskal, V., Davidová, A., Merhautová, V., \& Vrka, T. (2016). Fungi associated with decomposing deadwood in a natural beech-dominated forest. Fungal Ecology , 23 , 109-122. doi: 10.1016/j.funeco.2016.07.001

Blin, K., Medema, M. H., Kazempour, D., Fischbach, M. A., Breitling, R., Takano, E., \& Weber, T. (2013). antiSMASH 2.0-a versatile platform for genome mining of secondary metabolite producers. Nucleic Acids Research , 41 (W1), W204-W212. doi: 10.1093/nar/gkt449

Boddy, L. (2000). Interspecific combative interactions between wood-decaying basidiomycetes. FEMS Microbiology Ecology ,31 (3),185-194. doi:10.1016/S0168-6496(99)00093-8

Cantarel, B. L., Coutinho, P. M., Rancurel, C., Bernard, T., Lombard, V., \& Henrissat, B. (2009). The Carbohydrate-Active EnZymes database (CAZy): an expert resource for glycogenomics. Nucleic Acids Research , 37 , D233-D238. doi: 10.1093/nar/gkn663

Chen, L. F., Gong, Y. H., Cai, Y. L., Liu, W., Zhou, Y., Xiao, Y., ... Bian, Y. B. (2016). Genome sequence of the edible cultivated mushroom Lentinula edodes (shiitake) reveals insights into lignocellulose degradation.PLoS ONE 11 (8), e0160336. doi: 10.1371/journal.pone.0160336

Coates, D., Rayner, A. D. M. (1985). Fungal population and community development in cut beech logs. III. Spatial dynamics, interactions and strategies. New Phytologist , 101 (1), 153-171. doi: 10.1111/j.14698137.1985.tb02823.x

Devi, S., Kiesewalter, H., Kovács, T. R., Frisvad, J. C., Weber, T., Larsen, T. O., ... Ding, L. (2019). Depiction of secondary metabolites and antifungal activity of Bacillus velezensisDTU001. Synthetic and Systems Biotechnology , 4 (3), 142-149. doi: 10.1016/j.synbio.2019.08.002

de Wit, P. J. G. M., van der Burgt, A., Ökmen, B., Stergiopoulos, I., Abd-Elsalam, K. A., Aerts, A. L., ... Cox, M. P. (2012). The genomes of the fungal plant pathogens Cladosporium fulvum and Dothistroma septosporum reveal adaptation to different hosts and lifestyles but also signatures of common ancestry. PLoS Genetics , 8 (11), e1003088. doi: 10.1371/journal.pgen.1003088

[dataset] Eastwood, D. C., Floudas, D., Binder, M., Majcherczyk, A., Schneider, P., Aerts, A., ... Watkinson, S. C. (2011). The plant cell wall-decomposing machinery underlies the functional diversity of forest fungi. Science, 333 (6043), 762-765. doi: 10.1126/science.1205411

Edman, M., \& Eriksson, A. M. (2016). Competitive outcomes between wood-decaying fungi are altered in burnt wood. FEMS Microbiology Ecology , 92 (6), fiw068. doi: 10.1093/femsec/fiw068

Edman, M., \& Fällström, I. (2013). An introduced tree species alters the assemblage structure and functional composition of wood-decaying fungi in microcosms. Forest Ecology and Management ,306 (15), 9-14. doi: 10.1016/j.foreco.2013.06.023

Eichlerová, I., Homolka, L., Žif̌ćáková, L., Lisá, L., Dobiášová, P., \& Baldrian, P. (2015). Enzymatic systems involved in decomposition reflects the ecology and taxonomy of saprotrophic fungi. Fungal Ecology , 13 , 10-22. doi: $10.1016 /$ j.funeco.2014.08.002

Fernandes, A. F., Costa, L., Sousa, J. R., Zalocha, J., \& Almeida, M. G. (2019). Biological activities of marine-derived actinomycetes: testing the aqueous extracellular phase of Streptomyces aculeolatus. Annals of Medicine, 51 (sup1), 44. doi: 10.1080/07853890.2018.1561899

Floudas, D., Bentzer, J., Ahrén, D., Johansson, T., \& Tunlid, A. (2020). Uncovering the hidden diversity of litter-decomposition mechanisms in mushroom-forming fungi. The ISME Journal , 14 (8), 1-14. doi: 


\section{$10.1038 / \mathrm{s} 41396-020-0667-6$}

[dataset] Floudas, D., Binder, M., Riley, R., Barry, K., Blanchette, R. A., Henrissat, B., .. Hibbett, D. S. (2012). The Paleozoic origin of enzymatic lignin decomposition reconstructed from 31 fungal genomes. Science , 336 (6089), 1715-1719. doi: 10.1126/science.1221748

Friedemann, G., Leshem, Y., Kerem, L., Shacham, B., Bar-Massada, A., McClain, K. M., .. Izhaki, I. (2016). Multidimensional differentiation in foraging resource use during breeding of two sympatric top predators. Scientific Reports , 6 , 35031. doi: 10.1038/srep35031

Fukami, T., Dickie, I. A., Wilkie, J. P., Paulus, B. C., Park, D., Roberts, A., .. Allen, R. B. (2010). Assembly history dictates ecosystem functioning: evidence from wood decomposer communities.Ecology Letters , 13 (6), 675-684. doi: 10.1111/j.1461-0248.2010.01465.x

Fukasawa, Y., \& Matuoka, S. (2015). Communities of wood-inhabiting fungi in dead pine logs along a geographical gradient in Japan. Fungal Ecology , 18 , 75-82. doi: 10.1016/j.funeco.2015.09.008

García-Palacios, P., McKie, B. G., Handa, I. T., Frainer, A., \& Hattenschwiler, S. (2016). The importance of litter traits and decomposers for litter decomposition: a comparison of aquatic and terrestrial ecosystems within and across biomes. Functional Ecology , 30 (5), 819-829. doi: 10.1111/1365-2435.12589

Giweta, M. (2020). Role of litter production and its decomposition, and factors affecting the processes in a tropical forest ecosystem: a review. Journal of Ecology and Environment , 44 (1), 11. doi:10.1186/s41610020-0151-2

Herzog, C., Hartmann, M., Frey, B., Stierli, B., \& Brunner, I. (2019). Microbial succession on decomposing root litter in a drought-prone scots pine forest. The ISME Journal , 13 (2), 2346-2362. doi: 10.1038/s41396019-0436-6

Holmer, L., Renvall, P., \& Stenlid, J. (1997). Selective replacement between species of wood-rotting basidiomycetes, a laboratory study. Mycological Research , 101 (6), 714-720. doi: 10.1017/S0953756296003243

Huang, S. F., Chen, Z. L., Huang, G. R., Yu, T., Yang, P., Li, J., .. Xu, A. L. (2012). HaploMerger: reconstructing allelic relationships for polymorphic diploid genome assemblies. Genome Research, 22 (8), 1581-1588. doi: 10.1101/gr.133652.111.

Huang, S. F., Kang, M. J., \& Xu, A. L. (2017). HaploMerger2: rebuilding both haploid sub-assemblies from high-heterozygosity diploid genome assembly. Bioinformatics , 33 , 2577-2579. doi: 10.1093/bioinformatics/btx220.

Johnston, S. R., Boddy, L., \& Weightman, A. J. (2016). Bacteria in decomposing wood and their interactions with wood-decay fungi.FEMS Microbiology Ecology , 92 (11), fiw179. doi: 10.1093/femsec/fiw179

Jonkers, W., Rodriguez, E. A. E., Lee, K., Breakspear, A., May, G., Kistler, H. C. (2012). Metabolome and transcriptome of the interaction between Ustilago maydis and Fusarium verticillioides in vitro. Applied and Environmental Microbiology , 78 (10), 3656-3667. doi: 10.1128/AEM.07841-11

Katagiri, S., Shiba, T., Tohara, H., Yamaguchi, K., Hara, K., Nakagawa, K., ... Iwata, T. (2019). Reinitiation of oral food intake following enteral nutrition alters oral and gut microbiota communities. Frontiers in Cellular and Infection Microbiology , 9 , 434. doi: 10.3389/fcimb.2019.00434

Keller, N. P., Turner, G., \& Bennett, J. W. (2005). Fungal secondary metabolism - from biochemistry to genomics.Nature Reviews Microbiology , 3 (12), 937-947. doi: 10.1038/nrmicro1286

Kohler, A., Kuo, A., Nagy, L. G., Morin, E., Barry, K. W., Buscot, F., .. Martin F. (2015). Convergent losses of decay mechanisms and rapid turnover of symbiosis genes in mycorrhizal mutualists. Nature Genetics , 47 (4), 410-415. doi: 10.1038/ng.3223 
Konno, K. (2011). Plant latex and other exudates as plant defense systems: roles of various defense chemicals and proteins contained therein. Phytochemistry, 72 (13), 1510-1530. doi: 10.1016/j.phytochem.2011.02.016

Koren, S., Walenz, B. P., Berlin, K., Miller, J. R., Bergman, N. H., \& Phillippy, A. M. (2017). Canu: scalable and accurate long-read assembly via adaptive k-mer weighting and repeat separation. Genome Research , 27 (5), 722-736. doi: 10.1101/gr.215087.116

Krah, F. S., Seibold, S., Brandl, R., Baldrian, P., Muller, J., \& Bassler, C. (2018). Independent effects of host and environment on the diversity of wood-inhabiting fungi. Journal of Ecology , 106 , 1428-1442. doi: $10.1111 / 1365-2745.12939$

Lam, K. K., Labutti, K., Khalak, A., \& Tse, D. (2015). FinisherSC: a repeat-aware tool for upgradingde novoassembly using long reads. Bioinformatics , 31 , 1-8. doi:10.1093/bioinformatics/btv280

Lima, G., Arru, S., De Curtis, F., \& Arras, G. (1999). Influence of antagonist, host fruit and pathogen on the biological control of postharvest fungal diseases by yeasts. Journal of Industrial Microbiology and Biotechnology , 23 (3), 223-229. doi:10.1038/sj.jim.2900727

Li, T. C., Yu, L. Y., Song, B., Song, Y., Li, L., Lin, X., \& Lin, S. J. (2020). Genome improvement and core gene set refinement ofFugacium kawagutii . Microorganisms , 8 (1), 102. doi: 10.3390/microorganisms 8010102

Liu, Y. C., Jan, S., \& Bertil, S. (2013). Musket: a multistage k-mer spectrum-based error corrector for Illumina sequence data.Bioinformatics , 29 (3), 308-315. doi: 10.1093/bioinformatics/bts690

Martin, F., Kohler, A., Murat, C., Veneault-Fourrey, C., \& Hibbett, D. S. (2016). Unearthing the roots of ectomycorrhizal symbioses. Nature Reviews Microbiology , 14 , 760-773. doi: 10.1038/nrmicro.2016.149

[dataset] Martinez, D., Larrondo, L. F., Putnam, N., Gelpk,e M. D., Huang, K., Chapman, J., .. Rokhsar D. (2004). Genome sequence of the lignocellulose degrading fungus Phanerochaete chrysosporiumstrain RP78. Nature Biotechnology , 22 , 695-700. doi: 10.1038/nbt967

Mayjonade, B., Gouzy, J., Donnadieu, C., Pouilly, N., Marande, W., Callot, C., ... Munos, S. (2016). Extraction of high-molecular-weight genomic DNA for long-read sequencing of single molecules. Biotechniques , 61 (4), 203-205. doi: 10.2144/000114460

Moor, H., Norden, J., Penttil, R., Siitonen, J., \& Snll, T. (2020). Long-term effects of colonization-extinction dynamics of generalist versus specialist wood-decaying fungi. Journal of Ecology ,109 (1), 491-503. doi: $10.1111 / 1365-2745.13526$

Nagy, L. G., Riley, R., Tritt, A., Adam, C., Daum, C., Floudas, D., .. Larsson, K. H. (2016). Comparative genomics of early-diverging mushroom-forming fungi provides insights into the origins of lignocellulose decay capabilities. Molecular Biology and Evolution , 33 (4), 959-970. doi: 10.1093/molbev/msv337

Niego, A. G., Raspe, O., Thongklang, N., Charoensup, R., Lumyong, S., Stadler, M., \& Hyde, K. D. (2021). Taxonomy, diversity and cultivation of the Oudemansielloid/Xeruloid taxaHymenopellis , Mucidula , Oudemansiella, andXerula with respect to their bioactivities: a review. Journal of Fungi , 7 (1), 51. doi: $10.3390 /$ jof7010051

Niemela, T., Renvall, P., \& Pentilla, R. (1995). Interactions of fungi at late stages of wood decomposition. Annales Botanici Fennici ,32 (3), 141-152.

Oghenekaro, A. O., Kovalchuk, A., Raffaello, T., Camarero, S., \& Asiegbu, F. O. (2020). Genome sequencing of Rigidoporus microporus provides insights on genes important for wood decay, latex tolerance and interspecific fungal interactions. Scientific Reports , 10 (1), 5250. doi: 10.1038/s41598-020-62150-4

Park, Y. J., Jeong, Y. U., \& Kong, W. S. (2018). Genome sequencing and carbohydrate-active enzyme (CAZyme) repertoire of the white rot fungusFlammulina elastica. International Journal of Molecular Sciences , 19 (8), 2379. doi: 10.3390/ijms19082379 
[dataset] Ohm, R. A., Riley, R., Salamov, A., Min, B., Choi, I. G., Grigoriev, I. V. (2014). Genomics of wood-degrading fungi. Fungal Genetics and Biology, 72 , 82-90. doi: 10.1016/j.fgb.2014.05.001

[dataset] Olson, A., Aerts, A., Asiegbu, F., Belbahri, L., Bouzid, O., Broberg, A., ... Stenlid, J. (2012). Insight into trade-off between wood decay and parasitism from the genome of a fungal forest pathogen. New Phytologist , 194 (4), 1001-1013. doi: 10.1111/j.1469-8137.2012.04128.x

Polo, C. C., Pereira, L., Mazzafera, P., Flores-Borges, D. N. A., \& Meneau, F. (2020). Correlations between lignin content and structural robustness in plants revealed by x-ray ptychography. Scientific Reports , 10 (1), 6023. doi: 10.1038/s41598-020-63093-6

Qin, J., Horak, E., Popa, F., Rexer, K. H., \& Yang, Z. L. (2018). Species diversity, distribution patterns, and substrate specificity ofStrobilurus . Mycologia , 110 (3), 584-604. doi: 10.1080/00275514.2018.1463064

Rajala, T., Peltoniemi, M., Hantula, J., Makipaa, R., \& Pennanen, T. (2011). RNA reveals a succession of active fungi during the decay of Norway spruce logs. Fungal Ecology , 4 (6), 437-448. doi: 10.1016/j.funeco.2011.05.005

Rajala, T., Peltoniemi, M., Pennanen, T., \& Makipaa, R. (2010). Relationship between wood-inhabiting fungi determined by molecular analysis (DGGE) and quality of decaying logs. Canadian Journal of Forest Research , 40 (12), 2384-2397. doi: 10.1139/X10-176

[dataset] Riley, R., Salamov, A. A., Brown, D. W., Nagy, L. G., Floudas, D., Held, B. W., .. Grigorieva I. V. (2014). Extensive sampling of basidiomycete genomes demonstrate inadequacy of the white-rot/brownrot paradigm for wood decay fungi. Proceedings of the National Academy of Science, 111 (27), 9923-9928. doi: $10.1073 /$ pnas. 1400592111

Saha, P., \& Roy-Barman, S. (2018). The role of the global regulator of secondary metabolism laea in different fungi. Current Journal of Applied Science and Technology , 31 (1), 1-5. doi: 10.9734/CJAST/2018/45867

Sasha, V., \& Bhatnagar, J. M. (2019). An evolutionary signal to fungal succession during plant litter decay. FEMS Microbiology Ecology ,95 (10), fiz145. doi: 10.1093/femsec/fiz145

Sipos, G., Prasanna, A. N., Walter, M. C., O’Connor, E., Balint, B., Krizsan, K., .. Nagy L. G. (2017). Genome expansion and lineage-specific genetic innovations in the forest pathogenic fungiArmillaria . Nature Ecology and Evolution , 1 (12), 1931-1941. doi: 10.1038/s41559-017-0347-8

Šnajdr, J., Cajthaml, T., Valášková, V., Merhautová, V., Petránková, M., Spetz, P., .. Baldrian, P. (2011). Transformation of Quercus petraea litter: successive changes in litter chemistry are reflected in differential enzyme activity and changes in the microbial community composition. FEMS Microbiology Ecology , 75 (2), 291-303. doi: 10.1111/j.1574-6941.2010.00999.x

Song, Z. W., Vail, A., Sadowsky, M. J., \& Schilling, J. S. (2012). Competition between two wood-degrading fungi with distinct influences on residues. FEMS Microbiology Ecology , 79 (1), 109-117. doi: 10.1111/j.15746941.2011.01201.x

Stokland, J. N., Siitonen, J., \& Jonsson, B. G. (2012). Biodiversity in Dead Wood. Cambridge, UK: Cambridge University Press.

[dataset] Suzuki, H., MacDonald, J., Syed, K., Salamov, A., Hori, C., Aerts, A., .. Master, E. R. (2012). Comparative genomics of the white-rot fungi, Phanerochaete carnosa and P. chrysosporium, to elucidate the genetic basis of the distinct wood types they colonize. BMC Genomics , 13 , 444. doi: 10.1186/1471-2164$13-444$

Varga, T., Krizsán, K., Földi, C., Dima, B., Sánchez-García, M., Sánchez-Ramírez, ... Nagy L. G. (2019). Megaphylogeny resolves global patterns of mushroom evolution. Nature Ecology and Evolution , 3 (4), 668 678. doi: 10.1038/s41559-019-0834-1 
Vořišková, J., \& Baldrian, P. (2013). Fungal community on decomposing leaf litter undergoes rapid successional changes. The ISME Journal , 7 (3), 477-486. doi: 10.1038/ismej.2012.116

Walker, B. J., Abeel, T., Shea, T., Priest, M., Abouelliel, A., Sakthikumar, S., .. Earl, A. M. (2014). Pilon: An integrated tool for comprehensive microbial variant detection and genome assembly improvement. PLoS ONE , 9 (11), e112963. doi: 10.1371/journal.pone.0112963

Wang, P. M., \& Yang, Z. L. (2019). Two new taxa of the Auriscalpium vulgare species complex with substrate preferences. Mycological Progress , 18 (5), 641-652. doi: 10.1007/s11557-019-01477-3

Weng, C. H., Peng, X. W., \& Han, Y. J. (2021). Depolymerization and conversion of lignin to value-added bioproducts by microbial and enzymatic catalysis. Biotechnology for Biofuels , 14 , 84. doi: 10.1186/s13068021-01934-w

Wilson, C. L., Wisniewski, M. E., Biles, C. L., McLaughlin, R., Chalutz, E., \& Droby, S. (1991). Biological control of post-harvest diseases of fruits and vegetables: alternatives to synthetic fungicides. Crop Protection , 10 (3), 172-177. doi: 10.1016/0261-2194(91)90039-T

Zhang, L. Y., \& Wei, Y. L. (2016). Species diversity and distribution characters of wood-decaying fungi in Fenglin Nature Reverse. Chinese Journal of Ecology , 35 (10), 2745-2751. doi: 10.17520/biods.2018156

Zhao, H. X., Yan, B., Mo, S. M., Nie, S. Q., Li, Q. W., Ou, Q., ... Jiang, C. J. (2019). Carbohydrate metabolism genes dominant in a subtropical marine mangrove ecosystem revealed by metagenomics analysis. Journal of Microbiology , 57 , 575-586. doi: 10.1007/s12275-019-8679-5

Zhao, Z., Liu, H., Wang, C., \& Xu, J. R. (2013). Comparative analysis of fungal genomes reveals different plant cell wall degrading capacity in fungi. BMC Genomics , 14 (1), 274. doi: 10.1186/1471-2164-14-274

Zhu, N., Huang, W., Wu, D., Chen, K., \& He, Y. (2017). Quantitative visualization of pectin distribution maps of peach fruits.Scientific Reports , 7 (1), 9275. doi: 10.1038/s41598-017-09817-7

\section{Data Accessibility Statement}

The genomic data of our study were deposited in DDBJ/EMBL/GenBank including the A. vulgare(Accession number: JAHBBC000000000; BioProject: PRJNA728955; BioSample:SAMN19107592), A. microsporum(Accession number: xxxxxxx; BioProject: PRJNA735801; BioSample: SAMN19598194),A. orientale(Accession number: xxxxxxx; BioProject: PRJNA735804; BioSample: SAMN19598576),S. luchuensis(Accession number: xxxxxxx; BioProject: PRJNA735851; BioSample: SAMN19599093),S. pachycystidiatus(Accession number: xxxxxxx; BioProject: PRJNA735855; BioSample: SAMN19599128), S. stephanocystis(Accession number: xxxxxxx; BioProject: PRJNA735844; BioSample: SAMN19598582) and S. orientalis (Accession number: xxxxxxx; BioProject: PRJNA735858; BioSample: SAMN19599131).

\section{Author contributions}

Z.L.Y. designed the research; P.M.W. performed experiments, analyzed the data and wrote draft manuscript; J.P.X. and Gang Wu provided help and advice, and revised the manuscript; T.Z.L. provided samples for investigated the chemical compositions of pinecones.

\section{Figure legends}

Figure 1 Basidiomata and percentage of monthly occurrences of fruiting bodies of Auriscalpium and Strobilurus on pinecones. For the graphs, the x-axis shows months and the y-axis shows percentage of monthly occurrences of fruiting bodies on pinecones.

Figure 2 The distributions of genes encodingcarbohydrate-active enzymes (CAZymes) in $A u$ riscalpium and Strobilurus fungi.(a) wood decay fungi (WDF) plotted on the first two principal components from principal component analyses (PCA) of CAZymes. (b) Comparative analyses of CAZymes associated with lignocellulose decomposition. AAs: Auxiliary Activities; CBMs: Carbohydrate-Binding Modules; CEs: Carbohydrate Esterases; GHs: Glycoside Hydrolases; GTs: Glycosyl Transferases; PLs: Polysaccharide 
Lyases. (c) Heatmap analysis of CAZymes showing the distributions of CAZymes among different fungi. Numbers of family members in each genome are demonstrated. Overrepresented $(+4$ to 0$)$ and underrepresented (0 to -4) numbers are depicted as scores for each line in heatmap. The clustering on the left involves gene families with the same pattern in number. On the right is the name of the gene family.

Figure 3 Comparisons of thecarbohydrate-active enzymes (CAZymes) in Auriscalpium and Strobilurus, the proportions of four major chemical components in different cones, and the proportions of different enzymes encoded by lignocellulolytic genesin the two fungi groups. (a) Heatmap analysis of seven fungi inAuriscalpium and Strobilurus of CAZymes. (b) Four components of three different newly fallen cones. A, B, C and D in x-axis represent lignin, cellulose, hemicellulose and pectin, respectively. The $\mathrm{y}$-axis represents the proportion of the four components. (c) The proportions of lignocellulolytic genes in different fungi of Auriscalpium. A', B', C', D' in x-axis represent ligninase, cellulose, hemicellulose, pectinase respectively. The y-axis represents the proportion of the four types of enzymes; the same below. (d) The proportions of lignocellulolytic genes in different fungi of Strobilurus .

Figure 4 The changes of four major chemical components of cones before and after decomposition, and the relationship to differences of the numbers of lignocellulolytic genes between Strobilurus and Auriscalpium fungi colonizing the same pinecones. (a) The proportion of four components in cones of $P$. yunnanensisbefore and after the decomposition by $A$. orientale . A, B, C and D in $\mathrm{x}$-axis represent lignin, cellulose, hemicellulose and pectin, respectively. The $\mathrm{y}$-axis represents the proportion of the four components. White represents undecomposed cones, while gray represents decomposed cones. the same below. (b) The proportion of four components in cones of $P$. sylvestris before and after the decomposition by $A$. vulgare . (c) The content changes of four components in cones of $P$. armandii before and after being decomposed by $A$. microsporum . (d) Comparison of lignocellulolytic genes. A', B', C' and D' in $\mathrm{x}$-axis represent ligninase, cellulose, hemicellulose and pectinase, respectively. The y-axis represents the proportion of the four types of enzymes in $A$. orientalis and $S$. luchuensis grown on cones of $P$. yunnanensis . The same below. (e) Comparison of lignocellulolytic genes in $A$. vulgare and $S$.stephanocystis on cones of $P$. sylvestris . (f) Comparisons of lignocellulolytic genes of A . microsporum, $S$. pachcystidiatus and $S$. orientalis grown on cones of $P$. armandii . (g) Heatmap analysis of lignocellulolytic genes of four fungi on cones of $P$. subgenusPinus . (h) Heatmap analysis of lignocellulolytic genes of three fungi on cones of $P$. subgenus Strobus .

Figure 5 Types of successive decomposition of pinecones observed in the field. (a-b) The decomposition of cones of $P$. subgenus Pinus . (a) The cones decomposed by $A$. vulgare or $A$. orientale independently. (b) Successive decomposition and competition of $A$.orientale $/ S$. luchuensis and $A$.vulgare/S . stephanocystis on cones of $P$. subgenusPinus. The yellow brown pileus represents $S$.luchuensis or $S$. stephanocystis . (c-f) The decomposition of cones of $P$. subgenus Strobus . (c) The cones decomposed by $A$. microsporum independently. (d) Successive decomposition and competition of $A$. microsporumand $S$ . orientalis on cones of $P$. subgenus Strobus. The gray brown pileus represents $S$. orientalis . (e) Successive decomposition and competition of $A$. microsporum and $S$. pachcystidiatus on cones of $P$. subgenus Strobus - The yellow pileus represents $S$. pachcystidiatus . (f) Successive decomposition and competition of $A$. microsporum, $S$.pachcystidiatus and $S$. orientalis on cones of $P$. subgenus Strobus .

Table 1 The characteristics of the assembly scaffold and genomes of three Auriscalpium species and four Strobilurusspecies

\begin{tabular}{llllll}
\hline & A. vulgare & A. microsporum & A. orientale & S. stephanocystis & S. pa \\
\hline Strain No. & CBS 236.39 & A-H-210-14 & A-Y-A & CBS 113577 & Y-H- \\
Number of Contigs & 104 & 54 & 38 & 38 & 71 \\
Length of the genome assembly $(\mathrm{Mb})$ & 51.68 & 43.46 & 45.40 & 42.38 & 51.82 \\
Contig N50 $(\mathrm{Mb})$ & 1.721 & 2.449 & 1.814 & 2.875 & 2.269 \\
GC content $(\%)$ & 56.39 & 56.13 & 56.68 & 52.13 & 51.75 \\
Number of protein-coding genes & 13639 & 15333 & 16958 & 16439 & 1815
\end{tabular}




\begin{tabular}{llllll}
\hline & A. vulgare & A. microsporum & A. orientale & S. stephanocystis & S. pa \\
\hline Median / Average gene length (bp) & $1716 / 2202$ & $1862 / 2246$ & $1886 / 2300$ & $1702 / 2033$ & 1736 \\
Median / Average coding sequence size (bp) & $1392 / 1675$ & $1508 / 1801$ & $1535 / 1867$ & $1441 / 1721$ & 1446 \\
Median / Average number of exons per gene & $5 / 5.8$ & $6 / 7.1$ & $6 / 7.3$ & $5 / 6.7$ & $5 / 6.7$ \\
Median / Average exon size (bp) & $172 / 288$ & $144 / 252$ & $140 / 257$ & $143 / 256$ & $148 / 2$ \\
Median / Average intron size (bp) & $55 / 109$ & $55 / 71$ & $55 / 67$ & $52 / 53$ & $52 / 6$ \\
Median / Average size of intergenic regions (bp) & $674 / 1544$ & $399 / 1085$ & $386 / 953$ & $396 / 893$ & $454 /$ \\
Gene density (genes/Mbp) & 264 & 353 & 374 & 388 & 350 \\
\hline
\end{tabular}

Table 2. Abundance and distribution of the top 10 groups of overexpressed genes in the presence of latex among the seven sequenced genomes in this study

\begin{tabular}{lllllll}
\hline & InterPro Hit ID & InterPro Hit description & S. luchuensis & S. pachycystidiatus & S. stephanocystis & S. oriental \\
\hline 1 & IPR000209 & Peptidase S8 & 6 & 4 & 5 & 4 \\
2 & IPR001461 & Aspartic peptidase & 17 & 17 & 16 & 19 \\
3 & IPR008972 & Cupredoxin & 8 & 8 & 7 & 7 \\
4 & IPR001128 & Cytochrome P450 & 92 & 94 & 97 & 96 \\
5 & IPR018487 & Hemopexin-like repeats & 0 & 0 & 2 & 0 \\
6 & IPR015366 & Peptidase S53 & 1 & 1 & 0 & 1 \\
7 & IPR001338 & Hydrophobin & 31 & 0 & 27 & 37 \\
8 & IPR001128 & Cytochrome P450 & 4 & 9 & 4 & 11 \\
9 & IPR001338 & Hydrophobin & 42 & 41 & 49 \\
10 & IPR011701 & Major facilitator superfamily & 37 & & & \\
\hline
\end{tabular}

* significance at the level of $\mathrm{p}<0.05$.

${ }^{+}$adjusted p-value based on the False Discovery Rate (FDR) method for multiple testing correction.

Table 3 Comparison of secondary metabolisms of fungi inAuriscalpium and Strobilurus

\begin{tabular}{lllllll}
\hline Secondary metabolisms & S. stephanocystis & S. luchuensis & S. pachycystidiatus & S. orientalis & A. vulgare & A. orientale \\
\hline Terpene & 7 & 8 & 8 & 9 & 13 & 13 \\
T1PKS ${ }^{+}$-Terpene & 0 & 0 & 1 & 0 & 0 & 0 \\
T1PKS $^{+}$-NRPS-like & 0 & 0 & 0 & 0 & 1 & 1 \\
NRPS $^{++}$-like & 10 & 9 & 9 & 7 & 6 & 1 \\
Siderophore & 2 & 1 & 1 & 1 & 1 & 2 \\
betalactone & 0 & 0 & 0 & 0 & 1 & 1 \\
Strobilurin & 1 & 1 & 1 & 1 & 0 & 0 \\
T1PKS & 1 & 1 & 0 & 2 & 0 & 0 \\
indole & 1 & 1 & 1 & 21 & 0 & 0 \\
total & 22 & 21 & 21 & 22 & 18 \\
\hline
\end{tabular}

+ type I polyketide synthases.

${ }^{++}$nonribosomal peptide synthetase.

\section{Supporting Information}

Figure S1 The distribution characteristics of wood decay fungi in different degrees of decay in Fenglin 
Nature Reserve (data from Zhang and Wei 2016).

Figure S2 The successive decomposition of Pinus armandiicones by Auriscalpium and Strobilurus.

Figure S3 The abundance and distributions of lignocellulolytic genes of Auriscalpium and Strobilurus demonstrated by multidimensional clustering approaches.

Figure S4 Analyses of carbohydrate-active enzymes (CAZymes) and lignocellulolytic genes within genera of Auriscalpium and Strobilurusderived from heatmap, and principal component analyses (PCA).

Figure S5 Competitive relationshipes between fungi inAuriscalpium and Strobilurus on medium and cones.

Table S1. Gene distribution of carbohydrate-active enzymes (CAZymes) in Auriscalpium and Strobilurus fungi and the other 15 fungi.

Table S2. Raw data of four major chemical components of cones before and after decomposition by fungi in Auriscalpium .

Table S3. Statistical analyses revealed that the average number of carbohydrate-active enzymes (CAZymes) in Auriscalpium andStrobilurus fungi.

Table S4. The comparison of carbohydrate-active enzymes (CAZymes) between Auriscalpium and other WR fungi.

Table S5. The comparison of carbohydrate-active enzymes (CAZymes) between Strobilurus and other WR fungi.

Table S6. The collection information of fungi inAuriscalpium and Strobilurus .

Table S7. Sequencing statistics.

Table S8. Assessment of the protein gene set completeness inAuriscalpium and Strobilurus using BUSCO.

Table S9. Gene distribution of lignocellulolytic genes inAuriscalpium and Strobilurus fungi and the other 15 fungi.

Table S10. Statistical analyses revealed that the average number of lignocellulolytic genes in Auriscalpium andStrobilurus fungi. 

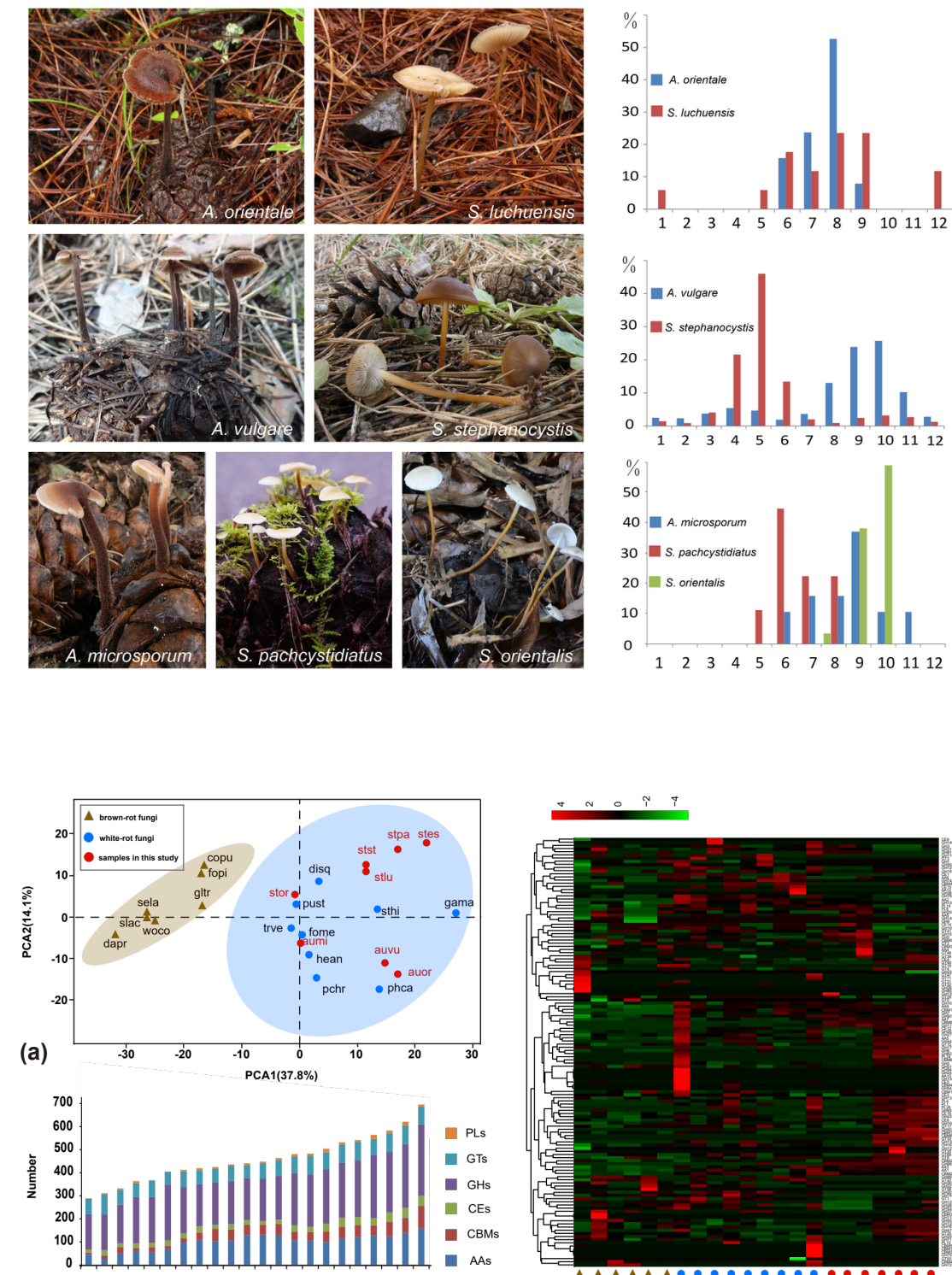

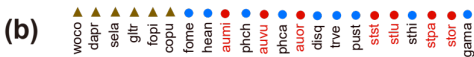

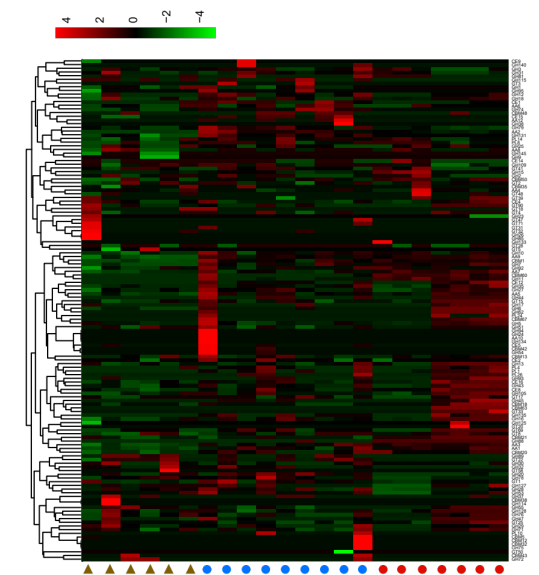

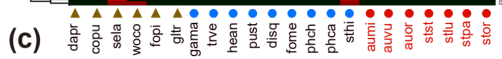



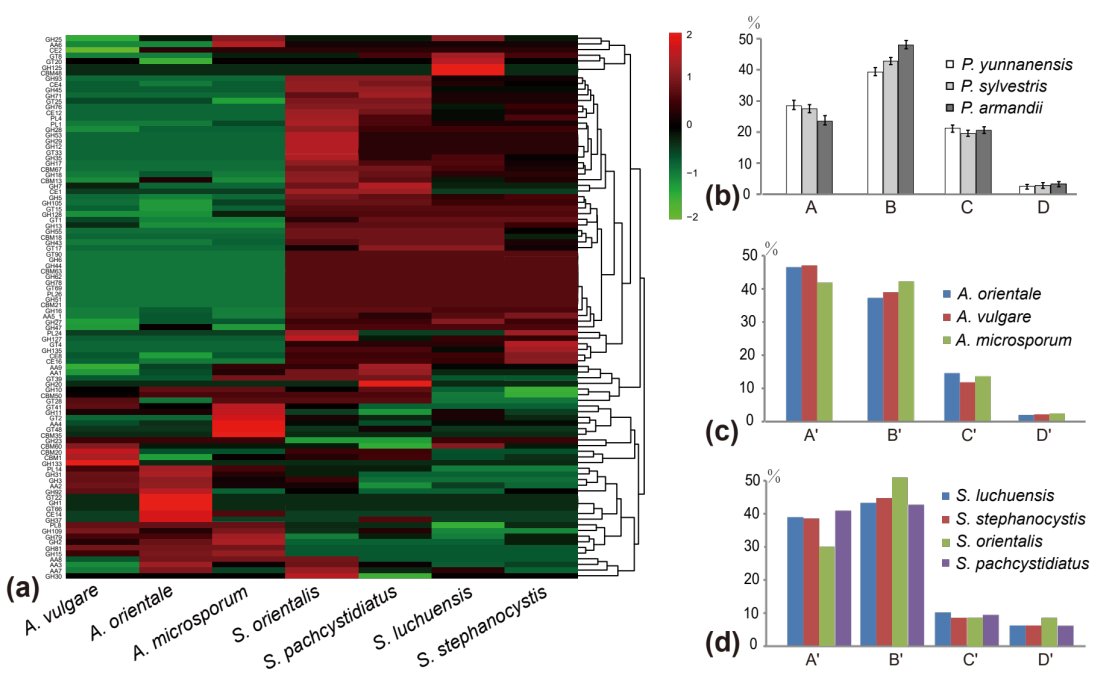

(a)

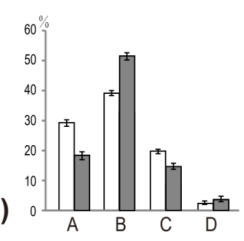

(b)

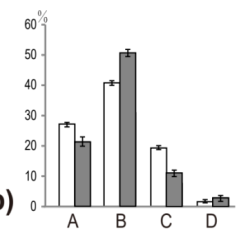

(d)

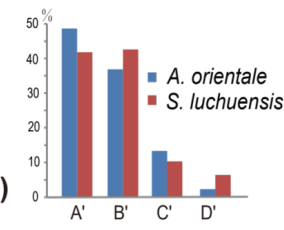

(e)

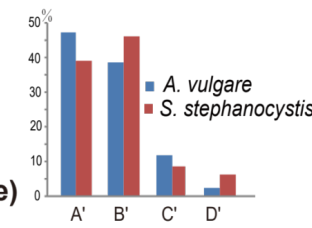

(g)

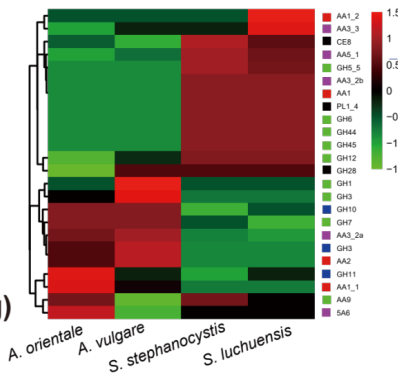

- Lignin Oxidase

- Lignin Degrading

- Cellulase

- Hemicellulase

- Pectinase
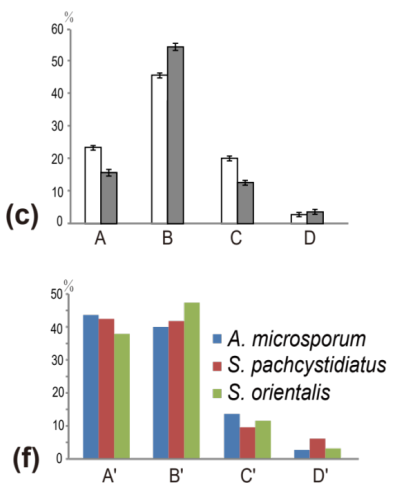

(h)

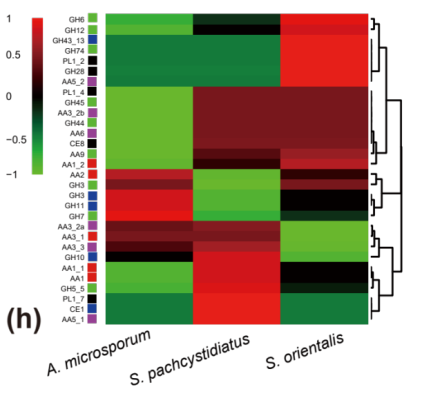




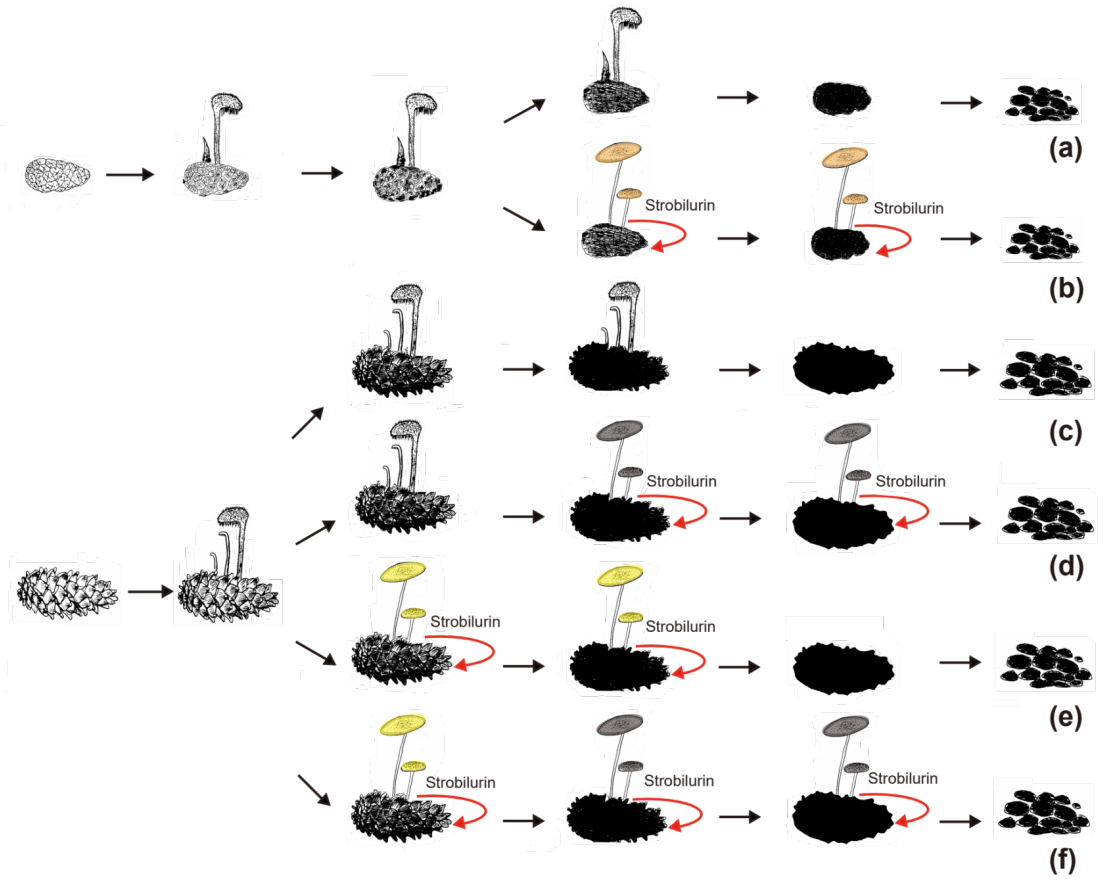

